Geografia e Ordenamento do Território, Revista Eletrónica

Centro de Estudos de Geografia e Ordenamento do Território

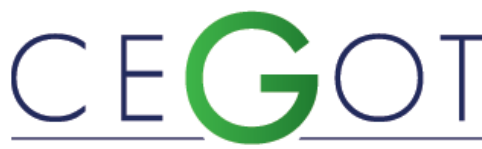

Centro de Estudos de Geografia

e Ordenamento do Território http://cegot.org

ISSN : 2182-1267

Nadais, $C$.

CEGOT

catnadais@hotmail.com

Santos, $N$.

Faculdade de Letras da Universidade de Coimbra

CEGOT

norgeo@ci.uc.pt

\title{
O lazer, o erotismo e a sociedade contemporânea
}

Referência: Nadais, C. e Santos, N. (2012). O lazer, o erotismo e a sociedade contemporânea. Revista de Geografia e Ordenamento do Território, n. 1 (Junho). Centro de Estudos de Geografia e Ordenamento do Território. Pág. 143 a 163

\section{Resumo}

Nos tempos pós-modernos, a velocidade marca passo, tanto nas atividades como nas relações pessoais, num ambiente de hiper-realidade potenciado pelas novas tecnologias. A virtualidade ganha importância numa época marcada por incertezas e como forma de saciar a necessidade de experiências de tensão e excitação, orientadas para uma lógica de consumo e de prazer, onde o risco, os limites e a tolerância podem sempre ser discutidos. É neste ambiente que crescem mercados, que pretendem ser resposta a esta procura de extremos e limites, com interesses controversos com tónica carnal. Neste trabalho apresentam-se lazeres hedonistas, e discute-se a forma como a sociedade entende e lida com o sexo e o erotismo, o uso do corpo, a norma, o desvio e a tolerância. 
Palavras-Chave: Lazer, Turismo, Erotismo, Sexualidade, Pós-Modernismo

\begin{abstract}
In postmodern times everything is happening fast, both in activities and in personal relationships in an environment of hyper-reality, enable by the new technologies. Virtual reality becomes important in these times of uncertainly, and a way to satisfy the need for experiences of tension and excitement, leading to consumption and pleasure, where the risk, tolerance and limits can always be discussed. Thus markets are growing, seeking to respond to this demand of extremism and limits, with emphasis on controversial practices with carnal interests. In this work, it's going to be presented the hedonistic leisure, and discussed how society understands and deal with sex and eroticism, the use of the body, the standard deviation and tolerance.
\end{abstract}

Keywords: Leisure, Tourism, Eroticism, Sexuality, Postmodernity 


\section{Introdução}

O sector do turismo e as diferentes atividades de lazer têm vindo a consolidar a sua importância, enquanto contributo para o crescimento positivo das economias. Nazareth (2007) considera que a economia do lazer tem uma especial importância quando se perspetiva um futuro de mudanças ao nível económico, numa época onde a atenção que antes era depositada no trabalho, se vai gradualmente orientando para a forma de ocupação dos tempos livres. O aumento da presença de atividades de lazer no quotidiano, intimamente relacionado com o aumento do tempo livre continuará a ter implicações nas sociedades. São sentidas novas tendências e novos produtos (Krippendorf, 1986, Poon 1993 e 1994 Netto \& Trigo, 2003), fruto da própria necessidade de diferenciação dos mercados e destinos (Ritchie \& Crouch, 2003), tendo em conta o mercado competitivo, bem como a disponibilidade para novas experiências e aumento da exigência por parte dos consumidores. Desta multiplicação de ofertas, surgem segmentos especializados - turismo de nicho -, envolvendo produtos, serviços e mercados cada vez mais distintos e improváveis, onde a imaginação e criatividade detêm grande importância (Novelli, 2005). As transformações que ocorrem na sociedade têm dado especial ênfase aos lazeres hedonistas, criando uma esfera de divertimento constante, de satisfação de desejos em cadeia, e de uma atribuição de importância ao momento, ao presente, exponenciado através da sua própria celebração, tal como define Langman (1992), características de uma sociedade hipermoderna (Lipovetsky, 2004), que centra no tempo (na sua violentação) a expressão fulcral da sua atuação, um tempo tanto passado como futuro, mas sempre efémero, fluido, híbrido.

O mercado relacionado com o fornecimento de serviços associados a práticas sexuais, surge na economia formal enquanto produto de lazer associado a práticas culturalmente desviantes mas crescentemente toleradas. A economia subterrânea, (negra) e, por vezes, a malva têm sido as responsáveis pela presença da oferta sexual nos mercados, de forma a suprir uma procura culturalmente enraizada. Inserindo-se numa área de atuação ainda pouco clara no que diz respeito ao que é norma e desvio, áquilo que é aceite ou não pela sociedade, a discussão do culturalmente desviante no 
lazer, explorado por Stebbins (1996 e 2008) e também por Santos (2011), é justificada pela necessidade da fuga a essa mesma norma, que espartilha o indivíduo que reclama autonomia e liberdade das suas escolhas e atos no âmbito espácio-temporal. 0 turismo sexual é uma atividade económica extremamente rendível, mas associada e verdadeiramente expressão de uma exploração humana muito invasiva e hedionda. Sabemos, contudo, que em algumas sociedades, relacionada com estratos sociais de elevados rendimentos, a emergência de situações de venda de serviços sexuais, mais ou menos explícitos, apresenta uma oferta significativamente organizada no mercado dito formal. Estes serviços estão intimamente ligados a um mercado de luxo, com estabelecimentos licenciados, serviços ao domicílio, acompanhamento para serviços sexuais, tanto em eventos sociais como de negócios. Esta gama de serviços é comummente associada a elevados valores acrescentados, com uma crescente importância económica e social e, na atualidade, sinónimo de escape e de experiências de hedonismo individualista. Na verdade, esta oferta sexual está relacionada com outras estruturas consideradas tradicionais de turismo e lazer, mas que se especializaram ou as apresentam de modo encapotado e/ou em função das clientelas alvo, desde as agências de viagens especializadas, empresas de eventos vocacionados para a oferta de produtos relacionadas com o sexo, os restaurantes exóticos que oferecem uma série de produtos gastronómicos associados à estimulação da libido, criando um ambiente de prazer explicitamente ancorado no desejo e erotismo. A juntar a estes estão, ainda, os estabelecimentos ligados ao ENTE (evening night time economy) (Santos \& Moreira, 2012), a criação de bares burlescos, a realização de festivais eróticos, a profusão de sex-shops e outras lojas temáticas, a oferta de programas de televisão, rádio e a própria imprensa especializada na divulgação erótica, sexual e nas atividades cor-de-rosa (um rosa cada vez mais choque mas, também, mais tolerado), são somente parte de uma lista de ofertas que se vai multiplicando a cada dia que passa.

Com este trabalho pretende-se discutir a presença do sexo e erotismo nas práticas de lazer da sociedade contemporânea, contextualizando e caracterizando este fenómeno, de forma a debater o modo como a sociedade entende e lida com estas experiências, numa época tanto potenciadora como justificadora destas práticas. De facto, todo o 
tempo, todo o espaço e todo o modo procuram transformar-se em meios de concretização de mais-valias e lucros substantivos e a ideologia capitalista do lucro encontra nesta atividade um campo muito fértil que leva ao aumento e diversificação da oferta, tal como alguma insensibilidade social e ampliação das escolhas do livrearbítrio nos leva a confrontá-la tolerantemente. Por ser um estudo exploratório, pretende tirar da abordagem a efetuar um ganho de familiaridade com o assunto, torná-lo mais explícito, contribuir para o enriquecimento das informações até hoje conhecidas, e constituir uma base para a elaboração de hipóteses de trabalho entendido como ponto de partida para estudos a efetuar. Pelo seu carácter qualitativo e interpretativo, devemos ressalvar a subjetividade de alguns assuntos, por se basear numa lógica indutiva e por se alicerçar num reduzido número de estudos científicos sobre o tema.

A falta de investigação metodologicamente orientada sobre a temática faz com que se propaguem mitos e se estigmatizem tanto os que oferecem como os que procuram esses serviços. A sua pertinência justifica-se pela crescente oferta materializada no aparecimento de novos serviços e de uma procura, que sem referências quantitativas fidedignas é, aparentemente, hoje mais visível cultural e socialmente. Entendemos o tema como relevante, no âmbito das ciências sociais e humanas, uma vez que faz parte da génese desta, da forma como a sociedade se comporta e como evolui, permitindo conhecer as transformações ocorridas nesta matéria. Apesar disso, é considerado um tema tabu, mas com grande atratividade resultante da nossa realidade e cultura, que sempre tornou o fruto proibido o mais apetecido e o mais desejado. Encontramo-nos numa sociedade em evolução, e consideramos que esta será uma das práticas que merecerá grande discussão nos próximos tempos, também associada à importância dada ao corpo e à sua imagem, tal como associado à evolução da participação social da mulher, enquanto pessoa que procura o seu próprio lazer e prazer, na aceção de igualdade de comportamento entre sexos. As relações mudaram, as formas de viver e conviver mudaram, e assim também as práticas sexuais e sua expressão simbólica. 


\section{O sexo e a sociedade}

Baudrillard (2011) $)^{1}$ considera o corpo como o mais belo objeto de consumo. O corpo é hoje a definição, através dos signos, do que somos e do que nos impõem. Queremos com isto dizer que, o corpo veste uma série de normas e de modas que a própria cultura nos inculca. O corpo foi, é e continuará a ser, alvo da própria evolução cultural, e a relação entre os corpos também sofre alterações cronológicas, e varia consoante o ponto do globo onde nos encontramos. Como refere Baudrillard (2011:165) "o modo de organização da relação ao corpo reflete o modo de organização da relação às coisas e das relações sociais". Le Breton (2002) expressa precisamente essa relação ao assumir que transformamos o nosso corpo num mapa de signos, numa bandeira, quando usamos os piercings e as tatuagens como forma de cartão de apresentação das próprias crenças e estilos de vida.

Segundo Baudrillard (2011), a altura em que o corpo ganha uma maior importância que a alma terá coincidido com o afirmar da sociedade de massas e consumo. Se antes era a alma que assegurava a salvação, nesta nova sociedade, só poderá ser assegurada se o corpo cumprir com os requisitos impostos pela sociedade, onde é mais importante o ter que o ser, sob pena de exclusão social se assim não for. Esta sociedade de espetáculo (Débord, 1991) é potenciadora e potenciada pela sociedade de consumo, numa dinâmica de constante necessidade e compensação entre ambas, com a finalidade de transformar o corpo num instrumento de prazer e metamorfose (Le Breton 2002).

Assim, o corpo consumidor de produtos obrigatórios e supérfluos, passa a ser, também, produto de consumo e espetáculo, potenciado por outros produtos e serviços. Devemos ainda referir que, e tal como defende Baudrillard (2011:173), o corpo se rege por definições de beleza, e por aquilo que é ditado pela cultura, pelos apelos hedonistas, e pelo erotismo. O mesmo autor (2011:175) considera que a sexualidade "orienta hoje por toda a parte a "redescoberta» e o consumo do corpo". Todavia, lembremos a liquefação descrita por Bauman (2008), em que a ligação

\footnotetext{
${ }^{1} 1$ a edição de 1970.
} 
amorosa entre os indivíduos, que tem vindo a repetir a própria dinâmica da sociedade, é marcada pela ausência do compromisso e da norma ou orientada por uma norma liquefeita, marcada pelo efémero, pelo momentâneo, pelo incerto. 0 amor líquido representa um novo paradigma das relações e da sociedade que repele tudo o que é sólido e duradouro, tudo que não se adapta à utilização imediata. Num mundo líquido, - amor tem que ser também diluído, porque desse modo pode ser melhor aproveitado. Os serviços eróticos e sexuais potenciam este modelo e criam produtos e necessidades em torno deste paradigma.

O sexo, entendido como relação sexual entre seres humanos, poderá, certamente, ser discutido sob diferentes perspetivas. Além da sua função reprodutora, é entendido normalmente como uma prática propiciadora de prazer e de deleite com o outro. Balandier (1985:57) afirma que "a sexualidade humana é um fenómeno social total: tudo se joga aí, se exprime aí, se estrutura aí desde o começo das sociedades". Das mais conservadoras às mais liberais, têm vindo a público práticas diversificadas e alternativas a uma rotina entre os elementos do casal, onde a literatura também assume presença contínua, como é o caso do livro do amor de referência, o vulgarmente conhecido como Kama Sutra. Antes de mais, destaquemos que aquilo que antes fazia parte da esfera estritamente íntima, se torna cada vez mais público e explícito, seja na realidade quotidiana, seja na forma como a sociedade comunica, ou mesmo nas representações que se fazem dela. No entanto, se tivermos em conta estudos sobre o tema, o sexo continua a ser tabu, ou pelo menos desconfortável para muitos. Michel (2009:34) refere que "a história ocidental reprimiu o corpo durante muito tempo e foi a troco de dolorosas lutas que o corpo e, depois, o sexo se libertaram".

Segundo Valerie Tasso", "hoje reprimimos o sexo, não por ocultação mas por sobreexposição", o que os especialistas chamam de "sobrecarga de estímulos e de intoxicação da vida privada" culpando os media, por venderem as representações das relações sexuais de tal forma que criam nos espetadores um sentimento de ansiedade,

\footnotetext{
${ }^{2}$ Citado por Michel (2009:33)

${ }^{3}$ In El Mundo, citado por Soares (2009:88), “Sexo nosso de cada dia” in revista Visão no 850 de 18 a 24 de Junho. Pp. 78-88
} 
perda de espontaneidade e auto-estima (Soares, 2009:80 e 88). Esta é também a posição de Michel (2009:60), que considera que "o universo do porno constitui em definitivo, um travão ao "bom orgasmo" e um impedimento ao desabrochar da sexualidade, o que só reforça os estereótipos e as frustrações de todo o género". Além disso, há autênticas campanhas de promoção do sexo, afirmando as suas vantagens tanto para o indivíduo como para os relacionamentos, assumido com qualquer outro produto no mercado.

Fala-se de uma hiper-sexualidade na sociedade, de uma banalização do acesso a imagens deste tipo, mas de uma forma que desvirtua a realidade, ou como afirma Pedro Mexia ${ }^{4}$ que "mostram uma faceta pesada e obscura, um vazio existencial, que contrasta com o espírito dos anos 1970, quando o sexo era percebido como libertador e festivo", coincidindo com a geração hippie, do amor livre. Esta hiper-sexualidade derivará certamente de uma hiper-realidade, caracterizada pela instantaneidade de satisfação de desejos e prazeres, pela procura do lazer fora, mas dentro de portas, criando uma realidade não real (um simulacro), e a uma alienação do que esta representa. Ao banalizarmos as práticas sexuais, e ao transferi-las para a esfera pública, criam-se outras, nomeadamente no que diz respeito ao consumo e ao lazer. De facto, a sua valorização é tal que a hipermodernidade nos afirma a importância da adultescência, uma juventude até morrer, porque todos querem manter a energia e comportamentos típicos da adolescência, independentemente da idade. E quando assim não acontece existem meios farmacológicos que a isso ajudam, como se pode perceber pelo sucesso de produtos comerciais como o Viagra, o Cialis ou o Levitra.

Não é pois anormal que o erotismo, enquanto forma de construção de fantasias, normalmente associadas ao desejo ${ }^{5}$, esteja muito mais presente nos discursos tanto do senso comum, como da ciência ou da política. Para Baudrillard (2011:175), deve entender-se o erótico enquanto "dimensão generalizada da permuta das nossas sociedades" do qual fazem parte um "código de símbolos". Este constrói imagens e proporciona a elaboração de momentos e fantasias que Bataille (1987:175) considera

\footnotetext{
${ }^{4}$ Citado por Soares (2009:88), “Sexo nosso de cada dia” in revista Visão no 850 de 18 a 24 de Junho. Pp. 78-88

${ }^{5}$ Sobre isto, Harris (2005:94) considera que "a fantasy arises when a person is able to identify in their imagination with a person or role in an ongoing event or store, and thus play a pleasurable part in it".
} 
como sendo "o mais intenso" e "situado no ponto mais elevado do espírito humano". O mesmo autor elabora uma longa discussão sobre o erotismo, sob três perspetivas, o erotismo dos corpos, o erotismo do coração e o erotismo do sagrado, sendo que em todas as esferas, "o desejo do erotismo é o desejo que triunfa do interdito" (Bataille, 1987:165) assumindo importância a relação entre as normas e a tolerância, como refere Stebbins (1996). Elias \& Dunning (1985:114) consideram ainda que " $a$ descoberta do outro sexo, a maior e mais excitante das experiências, de acordo com as normas e tradições da nossa sociedade é regulamentada de modo a ser um acontecimento único na vida pessoal", e que como alternativa se apresentam as representações miméticas destas experiências, "que movimentam e anima emoções".

As imagens, desde as mais simples ou ingénuas, podem representar um apelo às fantasias do ser humano, despoletado pela negação dessas tendências, consideradas normalmente mais irracionais, muito influenciado pelas discussões da religião, em relação ao uso dos corpos e da moralidade das práticas sexuais e dos desejos. A realidade mostra que os momentos de lazer estão cada vez mais associados ao hedonismo, senão vejamos o exemplo da viagem, que tem a si associado o sonho e o apelo à imaginação, em cenários distintos dos do quotidiano, e que nos levam a fantasiar, ou como nos diz Michel (2009:31) "a viagem é a concretização de uma fantasia ou um simulacro de alternidade".

\section{Lazer e Pós Modernidade}

Numa sociedade pós-moderna, associada ao que é imediato, provisório, superficial, descontinuado, desresponsabilizado, desumanizado e fortemente marcada pelo consumo (cujo tema foi largamente discutido por vários autores, como Rojek (1999 e 2005), Baudrillard (2011), Pais (1990), Hollands (1997), e Sennet (1998) e muitos outros), as práticas relacionadas com o sexo e o erotismo são recorrentes mas ainda merecedoras de grande atenção pela sociedade que continua com alguma dificuldade em as integrar num discurso aberto, se bem que algumas sociedades assumam já esse discurso, especialmente as mais tolerantes e menos puritanistas, como sucede nos países escandinavos. Todas as práticas de lazer associadas a estas noções, sempre 
estiveram envolvidas por mitos e preconceitos, que espartilharam uma sociedade que se regia por um discurso puritano tanto na sociedade europeia como na americana dos séculos XVIII e XIX, e que rejeitava estas necessidades e práticas, ao ponto de serem, e como refere Brás (s/d:43) “injustamente, (...) pouco abordadas, apesar da sua grande expressividade económico-social". No entanto, tal como refere Daley (2003:9), se o lazer e prazer não são sinónimos, devemos lembrar que o lazer é aquilo que é definido como um prazer legítimo.

Apesar de não ser uma prática nova, pouco se sabe oficialmente sobre os lazeres relacionados com o sexo e o erotismo em Portugal, talvez pelos preconceitos e estigmas que se associam a estas práticas. Não se conhece a sua dimensão, tanto da procura como da oferta e a sua multiplicidade de formas, em números oficiais, mas supõe-se que tenha uma grande importância económica.

Tratar de práticas de lazer de carácter sexual é normalmente, associado ao turismo sexual, que se baseia na oferta e procura de serviços desta índole, de mulheres, homens e crianças de forma ilegal, e automaticamente ao tráfico de seres humanos e exploração de menores, conotado a países do continente Asiático, Africano e SulAmericano. No entanto, já se conhecem outros contextos, onde estas práticas são assumidas, conhecidas e legisladas pelas sociedades, como é o caso de Nevada, onde os seus bordéis são permitidos pelas leis neoliberais do Estado, e portanto, é alvo de um controle muito mais acentuado, onde as questões de segurança são potencialmente garantidas (Brents; Jackson \& Hausbeck, 2010).

Já no território português, são indicadas como cidades associadas ao turismo sexual, Lisboa, Braga e Porto no artigo de Brás (s/d), e estudadas as cidades de Lisboa, Aveiro e Guarda, e colocadas em dúvida Funchal e Algarve no estudo de Santos et al (2007). De referir que este último estudo só se centrou nas atividades relacionadas com prostituição, sendo o seu interesse o tráfico de mulheres. No entanto, tanto pela natureza do tema e pelo secretismo das práticas, como dos escassos estudos que conhecemos sobre o assunto, é difícil apontar com certeza os destinos destas experiências. Além do mais, é do nosso interesse estudar outro tipo de atividades, que não estejam relacionadas com a prostituição, por considerarmos que as atividades que hoje são praticadas com este intuito apresentam uma diversidade de oferta e de 
públicos, sendo pertinente o seu conhecimento mais abrangente. Daqui decorre desde já a dificuldade da sua definição.

Não tivemos até agora acesso a estudos que se dediquem a este prisma da questão, e consideramos que o termo "turismo sexual" se debruça especialmente sobre práticas não desejadas se bem que toleradas pela sociedade, porque desrespeitam o ser humano. Aliás, os estudos realizados sobre esta temática são sempre acompanhados pela discussão de questões morais e de discussão de papéis, prepotência e submissão.

Consideramos também que se tratarmos estas como práticas desviantes, o poderemos fazer de forma demasiado generalizadora, ou de forma não suficientemente aprofundada. No entanto, uma discussão mais exaustiva de todas estas questões ultrapassaria todos os limites que temos estabelecido para a execução deste ensaio.

Uma conclusão poderemos desde já adiantar, no que diz respeito a estas práticas de lazer. Nelas são nitidamente sentidas as características de uma nova sociedade, associada às questões chave da velocidade, da simulação, do risco, da indiferença emocional, da insensibilidade, do fatalismo e da fantasia.

A partir do momento em que tratamos de um tema que levanta questões ao nível dos valores da sociedade, consideramos necessário perceber o que esta entende como correto e errado e como surge esse juízo, sobre práticas que não têm a si associadas um entendimento que envolva uma maioria significativa. Percebido como a fuga ao padrão, o desvio é hoje alvo de estudo, nomeadamente na área da sociologia. Para Clinard \& Meier (2011:4), tratamos de desvio quando a mesma situação é condenável por uns e louvada por outros, independentemente do caso ou assunto em discussão, se bem que, normalmente associado à moral. Este conceito surge em 1950, relacionado a estados de guerra, pobreza e comunidades instáveis. Cada vez mais, a sociedade cai na tendência da repetição, na homogeneização de comportamentos e consumos, exaltando o que é regra e rejeitando e reprovando outros que não aceites pela norma. Tal como refere Santos (2011:324), "demasiadas normas levam à procura de transgressão", e é neste campo que surgem as práticas apelidadas de desviantes ou de infração. 
Sobre esta discussão deveremos também lembrar Stebbins (2008 e 2009) e a classificação do lazer enquanto "casual" e "serious". Para este autor, antes de tudo deveremos ter definido o que é o desvio tolerável, que representam aquelas práticas que mesmo sendo controversas para a sociedade e para aquilo que esta considera moralmente correto, acontecem mas não despoletam grandes reações e reprovações, pelo menos que sejam significativas para haver um maior controlo da sociedade sobre essas experiências. Estes desvios toleráveis são associados ao prazer, e portanto classificadas como "casual leisure", e associadas ao sexo enquanto produto ${ }^{6}$. Já para Rojek (2005), estas práticas, quando discutidas moralmente relacionam-se com a fronteira entre o prazer de um e o sofrimento do outro ${ }^{7}$ enquanto ser explorador e explorado, além de que o prazer individual é frequentemente condenado e afastado do que é aceitável para a comunidade.

Santos (2011:324) considera que "a norma de uns é a transgressão de outros" e, por isso, concordamos com Clinard \& Meier (2011), que entendem este como um conceito difícil de definir, antes de mais, por ser exclusivamente sociológico. Por isto, os mesmos autores apresentam desvio sob quatro perspetivas ou entendimentos, que passamos a apresentar. Analisando a perceção do desvio estatisticamente, este é determinado como sendo aquilo que não faz parte das condições normais estabelecidas e, portanto, qualquer coisa que fuja estatisticamente ao padrão (moda) é considerado desvio. Por outro lado, uma definição absolutista já o identifica com base num juízo de valor sobre a continuidade de um padrão absoluto, seja pela tradição ou pelo costume. Uma outra definição é apresentada, denominando-se como reativista, onde o desvio surge quando a sociedade reage ao que não é normal, isto é, quando a diferença provoca uma reação no grupo. Por fim, a definição normativa, considera que o desvio depende diretamente da noção que é aceite pelo grupo como normal, a regra.

No domínio do lazer, tempo especialmente dedicado à fruição do tempo livre, não alienado e dependente do livre arbítrio e cada vez mais associado ao hedonismo,

\footnotetext{
${ }^{6} \mathrm{O}$ autor cita algumas destas práticas: “(...)cross-dressing, homosexuality, watching sex (striptease, pornographic films), and swinging and group sex" e faz referência também ao consumo excessivo de álcool, jogo e consumo de drogas. (Stebbins, 2009:27).

7 "The moral of all of this is that one person's pleasure is often another person's pain" (Rokek, 2005:42).
} 
surgem novos produtos em resposta a novas procuras, fora do que é o padrão, normalmente reclamando momentos diferentes, de excitação e de risco, onde também se integra o turismo aventura. Clinard \& Meier (2011:27) exploram os eventos desviantes, enquanto momentos onde a fuga à norma é internamente permitida e promovida, apresentando o exemplo do Mardi Gras, festa de Carnaval de New Orleans, que acontece desde 1889, onde as mulheres festejam mostrando os seus seios nus em troca de colares de contas. Os autores referem que este tempo e evento, que é criado para permitir esta exibição, são potenciados por outras variáveis, como "o álcool, o próprio ambiente de festa, o desejo de se envolver num risco momentâneo, $e$ um ambiente físico dissociado da atividade sexual". Assim, por considerarem que as práticas desviantes não acontecem por acaso, os lugares ganham uma importância relevante, a partir do momento em que também eles se tornam desviantes, e assim potenciem condutas que também o sejam. Os mesmos autores ${ }^{8}$ consideram ainda que se tem vindo a assistir a uma revolução sexual, por se registarem uma série de mudanças, que conferem uma maior permissividade em relação a questões sexuais. Desta forma, devemos ainda ter em conta que estes comportamentos são também orientados por normas estabelecidas pela sociedade, onde as religiões têm grande importância, e que variam consoante o contexto social onde são praticados.

Conhecida como Evening-Night Time Economy, o ambiente da noite é para muitos, lugar enquanto espaço de lazer noturno, e tempo de uma metamorfose e de libertação de quem a vivência. Funciona como um espaço isolado, onde as rotinas são quebradas ou esquecidas, onde a falta de luz confere mais sigilo, mais cumplicidade e maior permissão. Tal como referem Santos \& Moreira, $2008^{9}$, daqui decorrem as transgressões, os desvios, e as consequentes "alterações das normas de comportamento, através do prazer, da emoção e da excitação". Santos (2011:335), considera ainda que a noite "contém em si sementes de revolução social e cultural, atitudes em relação ao sexo e relacionamento inter-género e à superlativação do hedonismo".

\footnotetext{
${ }^{8}$ Clinard \& Meier (2011:343)

${ }^{9}$ Citado por Santos (2011:336)
} 
A cidade é então palco de práticas diversificadas, em grande parte ocupadas pelos jovens. Lembremos Hollands (1997), que no seu estudo relaciona a cidade com as identidades juvenis, bem como o seu consumo no âmbito do lazer. Num contexto de reestruturação económica, a cidade assume-se como um espaço de produção e afirmação de identidades culturais. Os jovens apropriam-se do espaço noturno, declaram-no como seu e usam-no para perpetuar um legado histórico (Geordie, no caso de estudo do autor), bem como instrumento de reafirmação de uma identidade, com algumas transformações, quando comparadas às suas bases, resultado de estratégias de afirmação das subjetividades individuais.

Segundo o mesmo autor, a cidade é considerada como um local importante para a expressão da modernidade, espaço público onde é bastante mais visível a exibição e para a reafirmação da identidade. Após o enobrecimento urbano que se deu durante o período de declínio económico mais acelerado, a cidade torna-se alternativa consistente ao sentimento de identidade. Além disso, estes espaços de consumo não discriminavam a população local, e esta apropria-se dos centros das cidades durante a noite, reclamando certas áreas como suas.

Para Hollands (1997), o fenómeno de "sair à noite", enquanto "rito de passagem" temporário, alargou-se em virtude do adiamento do casamento e da transição para a atividade profissional a tempo inteiro, criando uma espécie de perpétua pósadolescência (adultescência, acima referido). O mesmo autor encara este rito de passagem como um espaço mais permanente de formação de identidade, espaço esse que, não só implica elementos de uma cultura ocupacional tradicional reinventada, como também um envolvimento com "culturas de risco" alternativas, que, por seu turno, tendem a extravasar os limites daquilo que são os papéis aceitáveis em termos de classe e de género.

Consideramos que o espaço tem uma grande importância quando tratamos de práticas de lazer. Cada vez mais uma forma de economia, o lazer promove situações de trabalho em que os produtos oferecidos dependem, precisam de depender, de atividades remuneradas, associadas à qualidade, à certificação e ao profissionalismo. Todavia, todo este tempo se estrutura em torno de um espaço que tem por principal função promover a convivialidade, o hedonismo, a sociabilidade e propostas 
comportamentais especialmente associadas ao livre arbítrio. Assim, os tempos sociais, perante a procura e a qualificação que envolvem, precisam de uma diversidade de espaços que contribuam para a capacidade de atração dos produtos oferecidos. Como refere Sue (1982), o tempo de lazer torna-se produtivo, mas para isso é preciso valorizar os espaços que the estão agregados, recriando em cada um deles a diversidade e a diferença.

No espaço urbano há um enriquecimento quantitativo e qualitativo que é marcado pelas funções existentes, no tempo diurno diferentemente do tempo noturno. $O$ tempo livre torna-se referência de organização social e isso promove a recriação espacial, ampliada pela compressão do tempo/espaço que nos leva a lugares distantes (a diferentes escalas temporais; dia, semana, mês) e permite o desenraizamento sociocultural facilitador de práticas de lazer eróticas e sexuais.

Sabemos que toda a viagem tem um carácter exploratório e de descoberta. Quando se fala de lazer sexual e erótico essa valência ganha especial significado, já que os níveis de incerteza e de risco crescem, porque os tabus e as para-legalidades que lhe estão associados são normalmente muitos, especialmente nas sociedades ocidentais onde o ascetismo e o puritanismo se mantêm como orientação social.

Os lazeres exóticos e sexuais associam-se a estabelecimentos onde os prazeres mundanos, relacionados com a maior permissividade e a tolerância, onde a libertação pessoal, a celebração, o êxtase e a felicidade são as principais perceções a serem valorizadas. O forte sentido de identidade permite a criação de lugares de culto, uns com referências sociais positivas e outros com referências sociais negativas, que ganham nome e reconhecimento, e funcionam como elementos de marketing territorial para muitas "tribos urbanas" e para a população que procura a fuga à rotina, o escape e as novas experiências e participações características do novo turismo.

Na verdade, cada vez é mais fácil encontrar lazeres eróticos e sexuais, no pressuposto de que os empreendedores veem nesse investimento uma forma de estar no mercado e obter lucro. Ainda assim, a procura está cada vez está mais disposta a ir mais longe buscar serviços que não têm no seu espaço quotidiano. Na verdade, quando nos referimos às práticas de lazer, os lugares são, ao mesmo tempo, lugares de trabalho e 
lugares de fruição (Gama e Santos, 1992) onde se conjugam o tempo livre, o consumo e o lazer.

Atualmente, as atividades de lazer e o turismo, são reconhecidas como uma forma ou um meio viável para o desenvolvimento de qualquer território, já que uma das vantagens associadas é a obtenção de lucro e o enriquecimento da comunidade recetora devido aos significativos efeitos multiplicadores destas atividades. Estas práticas associadas ao erotismo e à sexualidade em situação de lazer estão mais presentes no ambiente urbano. Isto poderá dever-se ao maior grau de tolerância, aos maiores níveis de insensibilidade e à menor preocupação com a vida de vizinhos e elementos da comunidade onde se reside, que parece ser mais elevado no urbano do que no rural. Porém, algumas atividades, de oferta de serviços associados a clubes noturnos, discotecas e motéis especializados encontram nas periferias urbanas e no rural próximo a sua principal localização.

$\mathrm{Na}$ verdade, estes lazeres associados ao erotismo e à sexualidade representam, hoje, novidade e sofisticação. Não raro surgem como ambientes de exclusividade e associados a práticas exóticas. A sua localização é, também por isso mesmo, muito diversa e dependente de modas, sendo normal algum afastamento destes estabelecimentos de áreas de residência familiar e a sua aproximação de espaços onde a clientela potencial possa ser muito elevada, sem uma exposição demasiado explícita ao transeunte ou à população em geral.

Tendencialmente, e por razões óbvias de maior proximidade com o potencial consumidor, as práticas noturnas, como bares, discotecas, casas de espetáculo, casas de jogo, associadas aos já referidos negócios ENTE, tendem a localizar-se no centro da urbe, ou nos lugares que esta cria para o desenvolvimento deste tipo de negócio. Por outro lado, determinados estabelecimentos e lugares que têm conotação a este tipo de práticas, tendem a afastar-se do centro e a localizarem-se em zonas mais afastadas do centro da vida social, como os motéis, as "boîtes" ou as praias de nudismo ou naturismo, normalmente mais isoladas, com poucos acessos e rara sinalização. Encontramos ainda outro tipo de localização deste tipo de estabelecimentos, no centro da cidade, mas que tendem a preservar aquilo que se passa dentro de portas, evitando publicidades apelativas. Refira-se, ainda, que outras atividades simplesmente 
não revelam a sua localização ao público em geral, como são os casos dos estabelecimentos de troca de casais ou swing. O acesso a estes é só concedido por convite, depois do conhecimento de indivíduos que já estejam integrados nesse grupo e com o compromisso de respeitarem o secretismo imposto.

Devemos referir, no entanto, que no que diz respeito às práticas de lazer, em particular as associadas a temáticas como o sexo e o erotismo, nem todos se desenvolvem num espaço físico. A internet permite desenvolver uma série de práticas e mesmo relações virtuais. Também os serviços por telefone, a televisão e os filmes são hoje de muito fácil acesso à maioria da população. Desta forma, os espaços de lazer também têm sofrido uma transformação, onde a individualização das práticas dentro das paredes do lar é possível, de forma confortável, sigilosa e confidencial.

Seja por pudor ou vergonha, ou porque a sociedade o rejeita, admitir que se tem determinadas práticas é ainda uma dificuldade na sociedade dos dias de hoje. A realidade é que se multiplicam as ofertas de produtos sexuais e eróticos e tomam formas e funções diferentes das que são estabelecidas pelos mitos, de ajuda de relações sexuais conjugais. Definida como material virtual que faz referência explícita ao sexo, foi desde sempre representado pelas mais diversas culturas, figurando em mosaicos gregos e romanos, poesia, o Kamasutra indiano, baladas medievais, teatro francês, na arte, entre muitos outros (Clinard \& Meier, 2011).

"O sexo vende", é uma das frases que se entoam como se da maior certeza matemática se tratasse, e isso parece ganhar novas formas. O sexo e o erotismo estão presentes no quotidiano, nos mais diversos programas televisivos, imprensa, telefone, concursos, internet, eventos e espetáculos dos mais variados tipos, como os festivais motard, onde a presença de strippers é normalmente assegurada, nos Sex Festivals nas casas e ruas de "luz vermelha", em destinos de turismo sexual. Lembremos ainda Harris (2005:32) e o "corpo pós-moderno", que consegue ignorar o controlo social, e assim usar-se ou fazer-se usar de forma mais flexível que antes. Estas ganham forma através das práticas relacionadas com a estética, desde as cirurgias, dietética, ginásios, tatuagens e piercings, entre outros, que potenciam o corpo como produto. A fuga à rotina diária é um apelo constante dos que promovem o lazer e o turismo, e que asseguram essa possibilidade através destes. 


\section{Notas finais}

O prazer está francamente presente nas atividades de lazer, e a procura faz com que se multipliquem ofertas. O sexo e o erotismo foram e continuam a ser temas que se associam facilmente a tabus e proibições, já que muitas das práticas que lhes estão associadas, são consideradas transgressões a normas de bom funcionamento da sociedade. No entanto, são, hoje, vistas como práticas de lazer, crescentemente toleradas e representando para os sociólogos novas formas de relacionamento.

Para os estudos sobre o lazer, estas questões são muito pertinentes. Modo de negócio, em que inovação e exposição pública andam habitualmente de mãos dadas, por parte da oferta, as empresas de serviços eróticos e sexuais têm uma procura que assegura uma clientela que conjuga a tolerância social e a busca de novas experiências.

Numa sociedade pós-moderna, reafirmam-se tendências de fuga à regra e ao padrão, com as práticas de lazer a partilharem características que são o reflexo da sociedade transformada dos dias de hoje (fluída e líquida), onde a velocidade permite uma simultaneidade de acontecimentos (violentando o tempo), a multiplicação de oportunidades (diluindo as vontades) e o consumo compulsivo (simbólico e interminável). A insatisfação é motivação para a procura de novas experiências, mas os períodos de satisfação são cada vez mais curtos e as procuras mais obsessivas, promovidas pela publicidade e pelo marketing, que nos dá o que julgamos querer, saindo reforçado o sentido de imitação e simulação da realidade.

As práticas de lazer aqui discutidas levantam questões sobre as transformações da sociedade, do que decorrem também transformações nas próprias práticas sociais. Deparamo-nos com a possibilidade de um acesso a diferentes realidades em simultâneo, e assim a uma globalização das viagens, à simultaneidade de acontecimentos e a relações fugazes, momentâneas e instantâneas. Por outro lado, a oferta de lazeres reinventa os espaços e, não sendo suficientes, o espaço virtual tornase palco de novas experiências, nomeadamente de jogos sociais de simulação, associado a uma indiferença emocional pela busca da fantasia e risco, traduzindo-se em criativas formas de lazer, desviantes mas toleradas. 


\section{Referências bibliográficas}

Bataille, G. (1987). O Erotismo. Porto Alegre \& São Paulo: L\&PM editores. Tradução de António Carlos Viana.

Baudrillard, J. (2011). A Sociedade de Consumo. Lisboa: Publicações 70. Tradução de Artur Mourão.

Bauman, Z. (2008). Amor líquido. Relógio D’Água.

Brás, M. (s/d). "Contornos do turismo Sexual". Dos Algarves:43-37. Disponível em: www.dosalgarves.com/revistas/N14/7rev17.pdf (Abril 2012)

Brents, B. ; Jackson, C. \& Hausbeck, K. (2010). The State of Sex: Tourism, Sex and Sin in the New America Heartland. New York and London: Routledge.

Clinard, M. B. ; Meier, R. F. (2011). Sociology of Deviant Behavior. $14^{\text {th }}$ ed. Australia \& others: Wadswoth, Cengage Learning.

Daley, C. (2003). Leisure and Pleasure. New Zeland: Auckland University Press.

Débord, G. (1991). A sociedade do espetáculo. Cascais: Mobilis in Mobile, 1a ed. 1967.

Elias, N \& Dunning, E. (1985). A busca pela excitação. Lisboa: DIFEL 82. Tradução Maria Manuela Almeida e Silva.

Gama, A. \& Santos, N. (1992). Tempo livre, lazer e terciário. Cadernos de Geografia, 10. Coimbra: IEG.

Harris, D. (2005). Key concepts in leisure studies. London, California \& New Delhi: Sage. Hollands, R. (1997). As identidades juvenis e a cidade. Cidade, Cultura e Globalização. Fortuna, C. (org.). Oeiras: Celta.

Krippendorf, J. (1986) "The new tourist - turning point for leisure and travel". Tourism Management, 7 (2), 131-135.

Langman, L. (1992). Neon Cages. Shopping for subjectivity. Shiels, R. (Eds). Lyfestyle shopping. Londres: Routledge.

Le Breton, D. (2002). Conduites à risque. Paris: Presses Universitaires de France. 
Lipovetsky, G. e Charles, S. (2004). Os tempos hipermodernos. São Paulo: Barcarolla.

Michel, F. (2009). Planeta sexo - turismos sexuais, mercantilização e desumanização dos corpos. Porto: Campo das Letras.

Nazareth, L. (2007). The leisure economy: how changing demographics, economics and generational attitudes will reshape our lives and our industries. Canada: John Wiley \& Sons.

Netto, A. P. e Trigo, L. G. (2003) Reflexões sobre um novo turismo, São Paulo, Editora Aleph.

Novelli, M. (2005). Niche Tourism. Contemporary issues, trends and cases. Oxford: Elsevier.

Pais, J. M. (1990). "Lazeres e sociabilidades juvenis - um ensaio de análise etnográfica". Análise Social, 108/109: 591-644.

Poon, A. (1993) 1993 Tourism Technology and competitive strategies, Wallingford: CAB Internactional.

Poon,. A. (1994) "The 'new' tourist revolution". Tourism Management, 15 (2), 91-92.

Ritchie, J. R. B. \& Crouch, G. I. (2003). The competitive destination: a sustainable tourism perspective. Oxon: CABI Publishers.

Rojek, C. (1999). “Decentring leisure”. Rethinking leisure theory. London: Sage, pp. 79103.

Rojek, C. (2005). Leisure theory: principles and practices. New York: Palgrave Macmillan.

Santos, B. et al. (2007). Tráfico de mulheres em Portugal para fins de exploração sexual. Centro de Estudos Sociais. Faculdade de Economia. Universidade de Coimbra. Disponível em: http://www.caim.com.pt/cms/docs_prv/docs/DPR471dffd7ad591_1.pdf. (Janeiro de 2012)

Santos, N. (2011). "Desvios e regras nos territórios do quotidiano". Normas e Transgressão II. Imprensa da Universidade de Coimbra. 221-342 
Santos, N. e Moreira, C. (2012) "Evening/night-time leisure in Coimbra" Valença, M., Fernandes, J. A. R., Cravidão, F., Urban developments in Brazil and Portugal, Nova Publishers, Nova lorque.

Sennet, R. (1998). A corrosão do carácter. Lisboa: Terramar. Tradução de Freitas e Silva.

Soares, C. (2009). "Sexo nosso de cada dia". Visão no 850 de 18 a 24 de Junho, pp. 7888.

Stebbins, R. A. (1996) Tolerable Differences: Living with Deviance. Toronto: McGrawHill Ryerson

Stebbins R. A. (2008) Serious leisure. A perspective for our time. Londres: Transaction Publishers.

Stebbins, R. A. (2009). Leisure and consumption. Common Ground/Separate Worlds. New York: Palgrave Macmillan.

Sue, R. (1982). Vers une société du temps Libre? Sociologie d'Aujourdhui, Paris: PUF. 